\title{
Sobre delirios y ficciones
}

\author{
Fabián Andrés Gamba Sánchez \\ fa.gambas@gmail.com \\ Universidad de la Salle \\ Colombia
}

Fecha de recepción: 30/09/2013

Fecha de aprobación: 16/12/2013

\footnotetext{
Para citar este artículo: Gamba, F.A. (2013).

Sobre delirios y ficciones [reseña

de la novela ¿Profesor?, de Fabián Sanabria].

Ciudad Paz-Ando, 6(2), 168-171
}

Reseña de: ¿Profesor? Novela escrita por Fabián Sanabria (2013) y publicada por Taller de edición ROCCA, Bogotá. 424 páginas.
A continuación nos proponemos realizar una reseña de la novela del antropólogo y Doctor en Sociología, Fabián Sanabria. Si bien es cierto que reseñar una novela no es lo mismo que hacerlo con un texto "académico", podemos decir que la trayectoria del profesor Sanabria en el mundo universitario nos permite valorar su texto en esa doble acepción.

De un lado lo podemos entender como un ejercicio de ficción o "autoficción" como él mismo lo plantea en la introducción a su texto. Quien lea el documento también podrá reconocerlo como un ejercicio de las Ciencias Sociales; es más, podrá reconocerlo casi como un modelo de investigación cuyo objeto central es el sujeto-docente.

Lo dicho en el párrafo anterior pareciera referirse al trabajo de Pierre Bourdieu, Autoanálisis de un sociólogo, texto con el que por más literario que se proponga ser el profesor Sanabria, no podemos dejar de encontrar una correlación directa, lo que no debe sorprendernos, pues Sanabria ha insistido, en exceso y con énfasis, en su condición de ex alumno de Bourdieu. De hecho, se podría decir inclu- so que ha llegado a imitarlo, sobre todo en su afán de los últimos años por estar vigente en los medios de comunicación.

Con lo anterior no se quiere decir que la novela que estamos reseñando sea una imitación del ejercicio realizado por Bourdieu, pues muy lejos está el profesor Sanabria de la rigurosidad científica que caracterizó a Bourdieu, y que el autor de esta novela intentó imitar y defender en su tesis doctoral y algunos trabajos posteriores.

Como el objetivo es reseñar el texto, trataremos de ser cuidadosos en no develar su contenido, pues "dañaríamos" la intención de los lectores que se quieran acercar.

Para efectos prácticos, esta reseña tendrá dos partes muy distintas, una primera en la que hablaremos de los aspectos más formales del texto, para preparar al lector interesado en cuanto a lo que se va a encontrar en su ejercicio de lectura, y una segunda en la que se dará cuenta de la manera en que el autor fusiona el ejercicio de la auto reflexión con la escritura literaria. Sin pretender agotar el contenido de la novela, será necesario referir a algunos pasajes específicos de la misma; sin 
embargo, para hacer justicia a la propuesta del autor, haremos referencia a esos pasajes, sin recurrir a las citas; solo los narraremos como si fueran ficciones de quienes leímos las autoficciones del profesor Sanabria, pero siempre indicando al lector cuando estamos hablando de lo que el texto plantea.

Pero no hay que preocuparse por la posible filtración de contenidos del texto, pues nada de lo que digamos aquí es desconocido por aquellos que conocen la trayectoria del hoy director del ICAHN ${ }^{1}$, pues él ya se ha encargado de hacer público todo lo relativo a sí mismo; bien en sus constantes intervenciones en los medios de comunicación o a través de su conocido proyecto "El Tramoyero"?.

Cuando se toma el texto del profesor, su extensión pareciera, a simple vista, ser excesiva, y, sin el ánimo de invitar a que el texto no sea leído, debemos reconocer que es verdad, Sanabria hubiera podido decir exactamente lo mismo en no más de diez páginas, y, de haberlo hecho, tal vez hubiéramos contado con la fortuna de tener diez páginas bien escritas y no cuatrocientas veinticuatro. Alguien debería tener la bondad de comentarle al profesor que para plantear un nuevo estilo de escritura es necesario hacerlo con más cuidado y rigor.

El lector se encontrará (el autor lo aclara en su introducción) con un documento que carece de un signo de puntuación en particular, la coma, pues Sanabria ve poco necesario su uso, ya que señala a su texto como "un alegato sin pausa", y para no frenar su alegato suprime las comas e introduce en el texto pequeños espacios en blanco que luego llevan a una mayúscula.

Instituto Colombiano de Antropología e Historia

Si bien El Tramoyero es el nombre de la primera novela del profesor Sanabria, también lo es de un proyecto comunicativo que el mismo profesor desarrolla a través del sitio web YouTube. En este proyecto web, el profesor Sanabria presenta vídeos de corta duración donde comparte con su público asuntos relativos a su vida o a la del país.
Sin ánimo de juzgar, durante toda la lectura nos debatimos frente a esos espacios entre los errores de impresión y la confusión que parece tener el profesor Sanabria frente al uso de la coma, el punto y coma y el punto seguido. Sumado a esto, si se consultara con un experto en gramática o corrección de estilo, más de uno de los silencios del autor significarían un mal uso de la coma, del punto seguido y del punto y coma, pues los tres signos se diluyen en su muy innovadora apuesta por escribir como nadie más lo ha hecho.

Las Autoficciones (así dice el autor haber bautizado su serie de novelas que inició con El Tramoyero), bien podrían llamarse pretensiones, ensoñaciones, alucinaciones o simples especulaciones con referencia a una vida que el profesor Sanabria dice ser la suya, pero en la que por pura coincidencia encuentra el lector a un personaje central ya conocido, un niño de clase media-baja que logra llegar a las grandes esferas del mundo académico.

Debemos aclarar nuevamente que no estamos hablando de la vida de Pierre Bourdieu, sino de la que nos presenta el profesor Sanabria como suya.

Antes de abandonar los temas de forma, debemos señalar otro que causará curiosidad en el lector, pues se tienen dos formas de verlo. Para aquel lector que no esté familiarizado con el mundo de las Ciencias Sociales y/o que desconozca por completo quién es el profesor Sanabria, los múltiples nombres que aparecen en el texto de profesores, investigadores y autores, le parecerán producto de la ficción, pero para quienes contamos con cierta información, los nombres son tan claros que pareciera ser que el uso de la ficción abandonó en más de la mitad del texto al profesor Sanabria, pues no creemos que alguien cercano a las Ciencias Sociales no logre saber quién es, por ejemplo, Daniela Ligera, 
profesora francesa que trabaja temas de religión y creencias ${ }^{3}$.

Ahora bien, todo lo anterior no puede hacernos olvidar que el texto tiene una intencionalidad y es la de enunciar, a manera de biografía intelectual, las razones por las que Fabián Sanabria llegó a la docencia y las maquinarias que puso en marcha con la intención de hacerse Profesor Titular en la Universidad Nacional de Colombia.

La autoficción del profesor Sanabria nace de una enfermedad que lo llevó a estar por varios días en cuidados intensivos y que según él, le permitió ver en retrospectiva lo que había sido su vida; extraña retrospectiva que solo le mostró al profesor su pasado en clave de búsqueda profesional, clave que lo hace ver como un ser humano sin pretensiones y sin una mayor búsqueda que la de la felicidad.

Pero lo importante aquí no es la vida personal del profesor Sanabria, que poco o nada puede interesarle a muchos pero que innegablemente daría para más de una polémica. Tampoco vamos a seguir el juego sucio que propone el autor de la novela ni nos vamos a ir por la ramas de su homosexualidad o su relación con El infantino, expresión utilizada por él mismo para referirse a lo largo del texto a su pareja, y de la cual podríamos hacer toda una apología a la dominación, el maltrato y los aíres de superioridad de nuestro autor. Y lo llamamos juego sucio porque no podemos olvidar aquel momento (que también narra en su novela) en el que Sanabria, frente a las críticas sobre su extraña elección como Decano en la Universidad Nacional, solo supo decir que quienes estaba en su

\footnotetext{
3 Podemos equivocarnos pero, en este caso particular se está hablando de la Profesora Danièle Hervieu-Léger, reconocida socióloga francesa enfocada en la sociología de la religión y a quien el profesor Sanabria hace constante referencia en su tesis de doctorado; solo usamos este nombre como ejemplo pues son muchos los que el profesor Sanabria intenta cambiar sin mayor éxito.
}

contra lo hacían por su condición de homosexual (nada más alejado de la realidad).

En vista de lo anterior, empieza a parecer un cliché la cantidad excesiva de referencias a la orientación sexual del autor, como si quisiera blindarse de antemano a cualquier posible crítica, pensando en que este tema sería el centro de la misma.

Ahora sí lo importante, la reflexión sobre la práctica docente que hace Sanabria en su texto es la impostura ${ }^{4}$ docente, la preocupación que da origen a estas más de cuatrocientas páginas. Detrás del relato del profesor Sanabria, se encuentra la voz de un narrador eufórico y apasionado que quiere develarnos dos grandes secretos sobre el mundo universitario.

En primer lugar, nos quiere contar por vez primera, que el mundo de la docencia universitaria es un escenario demarcado por el prestigio que dan los títulos y las relaciones de compadrazgo que se pueda gestar alguien a lo largo de su vida, cosa que ya hemos leído en muchos otros escenarios, entre ellos varios textos del ya muy nombrado (en esta reseña) Pierre Bourdieu. De igual manera, el profesor Sanabria nos revela el gran secreto oculto (solo para él) detrás de la noción de profesor, pues señala que la idea de profesar, que proviene del mundo religioso, da la sensación de tener a un sujeto dueño de los conocimientos que se enfrenta a otros muchos que, sin conocimientos, buscan en él la verdad revelada.

El autor de ¿Profesor? nos propone una formula interesante y nos indica que es preferible hablar de equivocaciones, experiencias y aprendizajes, pues nadie en un salón de clase es del todo ajeno al saber, y que la relación en el aula es un ejercicio de múltiples aprendizajes dialógicos.

\footnotetext{
4 Utilizamos la expresión impostura y no autoficción, porque se nos hace más preciso el concepto, aunque en el texto reseñado nunca se trabaje la noción de impostura o impostor.
} 
Creemos necesario recomendar al profesor Sanabria y a otros tantos docentes universitarios una revisión (no necesariamente exhaustiva) sobre los avances que los investigadores en pedagogía y didáctica han hecho sobre temas de docencia y la relación enseñanzaaprendizaje, pues descubrirían que es mucho lo que ya se ha avanzado sobre un tema que hasta ahora están empezando a conocer quienes ejercen como profesadores iluminados por el prestigio de un diploma.

Al finalizar la lectura de la "novela", queda una sensación que esperamos algunos lectores más compartan: si la reflexión sobre un tema tan importante como la docencia es tan pobre en alguien que tiene la formación de Fabián Sanabria, quien además por su propia decisión es docente, ¿no sería bueno que el profesor aprovechara ese viaje al pasado y optara por reflexionar sobre cómo ser astronauta o chofer de Trolebús? Quizás de esta manera, Sanabria encontraría un lugar menos complicado para la ubicación intelectual de sus autoficciones.
No podemos dejar de mencionar en este texto, la adaptación tan poco decorosa que hace el profesor Sanabria de la obra de Walter Benjamin. Para quienes algo hemos leído de y sobre Benjamin, es fácil recordar la versión que el autor alemán hace del cuento de la Bella durmiente, con la que prologa el texto con el que trató de lograr una plaza de profesor y que fue rechazado por la incomprensión de sus lectores ${ }^{5}$.

En aquella versión de la Bella durmiente, Benjamin se señala a sí mismo como un pretencioso que intentó entrar en un mundo que no le correspondía, vistiendo una toga de profesor cuando no era más que el cocinero de palacio. Quien no note la misma idea en la razón por la cual Fabián Sanabria señala que su novela no fue aceptada para convertirse en Profesor Titular de la Universidad Nacional, podría estar leyendo solo el texto y no fijando su atención en el pretexto: un intelectual que quiere hacer de sus ideas un producto masivo y que ha descubierto (de manera tardía) que el arte tiene un mayor público que la ciencia.

\section{Referencias Bibliográficas}

- Benjamin, W. (1990). El origen del drama barroco alemán. Madrid: Altea, Taurus, Alfaguara

- Bourdieu, P. (2006). Autoanálisis de un sociólogo. Madrid: Anagrama

- Bourdieu, P. (2008). Homo Sociologicus. Buenos Aires: Siglo XXI editores.

- Sanabria, F. (2012). El Tramoyero. Bogotá: Taller de Edición ROCCA. 